\title{
Renin-angiotensin-aldosterone system peptide profiles in patients with COVID-19
}

\author{
Alexander Kutz 1,2,*, Anna Conen 1,3,*, Claudia Gregoriano', Sebastian Haubitz, ${ }^{1,3}$, Daniel Koch', \\ Oliver Domenig ${ }^{4}$, Luca Bernasconi5, Beat Mueller ${ }^{1,2,6}$ and Philipp Schuetz ${ }^{1,2,6}$
}

${ }^{1}$ Division of General Internal and Emergency Medicine, ${ }^{2}$ Division of Endocrinology, Diabetes, and Metabolism, ${ }^{3}$ Division of Infectious Diseases and Hospital Hygiene, University Department of Medicine, Kantonsspital Aarau, Aarau, Switzerland, ${ }^{4}$ Attoquant Diagnostics GmbH, Campus-Vienna-Biocenter, Vienna, Austria, ${ }^{5}$ Institute of Laboratory Medicine, Kantonsspital Aarau AG, Aarau, Switzerland, and ${ }^{6}$ Faculty of Medicine, University of Basel, Basel, Switzerland

*(A Kutz and A Conen contributed equally to this work)

Correspondence should be addressed to A Kutz Email

kutz.alexander@gmail.com

Abstract

Objective: While evidence on the interface between severe acute respiratory syndrome coronavirus 2 (SARS-CoV-2) infection and the renin-angiotensin-aldosterone-system (RAAS) is accumulating, clinical data on RAAS peptide alteration among coronavirus disease-19 (COVID-19) patients is missing.

Design and methods: In this exploratory study, we prospectively included adult patients (aged $\geq 18$ years) admitted between February 26 and April 30, 2020 to a tertiary care hospital in Switzerland. We assessed the association of an underlying SARS-CoV-2 infection and equilibrium serum levels of RAAS peptides in hospitalized COVID-19 patients 1:1 propensity-score matched with patients suffering from SARS-CoV-2-negative respiratory infections. Subgroup analyses involved stratification for taking RAAS inhibitors.

Results: COVID-19 patients had about 50\% lower equilibrium serum RAAS peptide levels as compared with matched controls (angiotensin I: 31.6 vs $66.8 \mathrm{pmol} / \mathrm{L},-52.7 \%$ (95\% Cl: $-68.5 \%$ to $-36.9 \%)$; angiotensin II: $37.7 \mathrm{vs} 92.5 \mathrm{pmol} / \mathrm{L}$, $-59.2 \%$ ( $95 \% \mathrm{Cl}:-72.1 \%$ to $-46.3 \%)$; angiotensin (1-5): 3.3 vs $6.6 \mathrm{pmol} / \mathrm{L},-49.7 \%$ ( $95 \% \mathrm{Cl}:-59.2 \%$ to $-40.2 \%)$; angiotensin (1-7): $4.8 \mathrm{vs} 7.6 \mathrm{pmol} / \mathrm{L},-64.9 \%(95 \% \mathrm{Cl}:-84.5 \%$ to $-45.3 \%))$. While the plasma renin activity was lower in COVID-19 patients ( 88.6 vs $207.9 \mathrm{pmol} / \mathrm{L}$, $-58.5 \%$ (95\% Cl: $-71.4 \%$ to $-45.6 \%)$ ), there was no difference of angiotensinconverting enzyme (ACE) and ACE2 plasma activity between the groups. Subgroup analyses revealed a pronounced RAAS peptide profile depression in COVID-19 patients among those not on RAAS inhibitors.

Conclusions: As compared with SARS-CoV-2-negative patients, we found a downregulated RAAS in presence of a SARS-CoV-2 infection. Whether the lower levels of the protective angiotensin (1-5) and (1-7) are linked to adverse outcomes in COVID-19 warrants further investigation.

\section{Introduction}

The renin-angiotensin-aldosterone system (RAAS) involves a cascade of vasoactive peptides that are pivotal to the homeostasis of the cardiovascular and respiratory system. Importantly, the severe acute respiratory syndrome coronavirus 2 (SARS-CoV-2) utilizes and interrupts this pathway directly through modulation of angiotensin-converting enzyme 2 (ACE2) $(1,2)$. ACE2 not (c) 2021 European Society of Endocrinology Printed in Great Britain
European Journal of Endocrinology

(2021) 184, 543-552 only acts as an enzyme countering RAAS activation but is also a functional receptor on cell surfaces for both SARS$\mathrm{CoV}$ and SARS-CoV-2 (3), highly expressed in the lung and heart (1). Following binding, the activity of ACE2 was hypothesized to be subsequently downregulated through multiple mechanisms, such that the enzyme is limited to exert protective effects in organs (4).

Published by Bioscientifica Ltd. 
As known from preclinical studies, downregulation of alveolar ACE2 activity facilitates neutrophil infiltration in response to bacterial endotoxin (5) and may result in unopposed angiotensin II accumulation and local RAAS activation. In humans, however, it is still debated to what extent angiotensin II activity increases, especially after a SARS-CoV-2 infection, and whether this postulated increase is associated with organ injury and severity of COVID-19 (6).

At the beginning of the pandemic, it was hypothesized that RAAS inhibitors could upregulate the expression of ACE2 in the respiratory tract (7), thereby facilitating infection with SARS-CoV-2 and developing a more severe course of illness, but no clinical data supported this hypothesis so far $(8,9)$.

RAAS peptides are dynamically equilibrated across different human tissues and health conditions and might respond differently to pharmacologic alteration through RAAS inhibitors. While the intersecting network of regulatory and counterregulatory circulating RAAS peptides has been reported repeatedly in the physiological state, only few concordant data have been shown in COVID-19 patients (10).

Thus, we first sought to determine RAAS peptide levels among patients with and without COVID-19 and, secondly, to investigate the association between the use of RAAS inhibitors and levels of RAAS peptides.

\section{Subjects and methods}

\section{Patient population}

We identified all patients who underwent SARS-CoV-2 testing between February 26 and April 30, 2020, because they presented with symptoms of respiratory infection in a Swiss tertiary care center. Patients were deemed to suffer from COVID-19 if any test was positive for SARS-CoV-2 RNA and suffering from another respiratory infection (no COVID-19) if SARS-CoV-2 RNA or serology were negative. We excluded non-medical, psychiatric, and non-adult $(<18$ years of age) patients.

\section{Study design and setting}

We conducted a prospective observational study using patient data from our hospital that were collected during the first pandemic peak in Switzerland. Baseline characteristics of our COVID-19 cohort were published elsewhere (11). In brief, COVID-19 was defined by a positive real-time RT-PCR taken from nasopharyngeal swabs or lower respiratory tract specimens according to WHO guidance (12). To qualify for study inclusion, patients must have provided general informed consent. The institutional review board of Northwestern Switzerland approved this study (EKZN, 2020-01306). This study followed the Strengthening The Reporting of OBservational studies in Epidemiology (STROBE) reporting guideline.

\section{Data collection}

Demographic and clinical baseline characteristics were assessed as part of the clinical routine during the hospitalization and were extracted from the electronic health records. Experimental treatment was offered to all COVID-19 patients and included hydroxychloroquine only (first line) and tocilizumab. Azithromycin was used in patients transferred from France. The remaining therapy was upon clinical decision making of the treating physicians. As part of the clinical routine, we assessed the age-adjusted Charlson Comorbidity Index (13) and the Clinical Frailty Score (14), respectively.

\section{Laboratory analysis}

Routine laboratory parameters were measured at the central laboratory of our hospital.

To test for SARS-CoV-2 RNA, the Allplex ${ }^{\mathrm{TM}}$ 2019nCoV Real-time PCR by Seegene (Korea) (15) was used. In the clinical evaluation study the efficacy of the test was compared with Centers for Disease Control and Prevention (CDC's) predicate and showed a 100\% (95\% CI: 93-100\%) positive percent agreement and a $94 \%$ (95\% CI: 87-98\%) negative percent agreement for upper respiratory samples.

Left-over routine blood samples were stored at $-80^{\circ} \mathrm{C}$ to assess RAAS peptides in a batch analysis. The equilibrium levels of angiotensin I, angiotensin II, angiotensin (1-7), and angiotensin (1-5) in human serum/heparinized plasma samples were quantified by liquid chromatographymass spectrometry/mass-spectroscopy (LC-MS/MS) using previously validated methods $(16,17)$. In short, serum/plasma conditioning for equilibrium analysis was performed at $37^{\circ} \mathrm{C}$ followed by stabilization through the addition of enzyme inhibitors (Attoquant Diagnostics, Vienna, Austria). The biochemical background of the equilibrium approach has been described recently (17). Stabilized equilibrated serum/plasma samples were further spiked with stable isotope labeled internal standards for each angiotensin metabolite $(200 \mathrm{ng} / \mathrm{mL})$. The samples 
finally underwent C-18-based solid-phase-extraction and were subjected to LC-MS/MS using a reversed-phase analytical column operating in line with a Xevo TQ-S triple quadruple mass spectrometer (Waters, Milford, Massachusetts, USA). Internal standards were used to correct for peptide and steroid recovery of the sample preparation procedure for each analyte in each individual sample. Analyte concentrations were reported in (pmol/L) and calculated considering the corresponding response factors determined in appropriate calibration curves in original sample matrix, on condition that integrated signals exceeded a signal-to-noise ratio of 10 . Renin activity marker, ACE and ACE2 were calculated, based on the angiotensin levels (plasma renin activity (PRAS): (eq-angiotensin I+eq-angiotensin II); ACE activity: (eq-angiotensin II/eq-angiotensin I); ACE2 activity: (angiotensin (1-5)/angiotensin II) (17). Previous literature has shown excellent correlation between plasma renin activity and (eq-angiotensin I+eq-angiotensin II) levels by equilibrium assays with a $\mathrm{r}^{2}$ of $0.85(P<0.001)(18)$. Similar, (eq-angiotensin II/eq-angiotensin I) levels have already served as a valid surrogate marker for circulating ACE activity in previous studies (19), and (angiotensin (1-5)/angiotensin II) levels for circulating ACE2 activity (20).

\section{Statistical analyses}

Categorical variables are expressed as numbers (percentage) and continuous variables as means ( \pm S.D.) or medians (interquartile range (IQR)) as appropriate. To address confounding by indication and other sources of bias arising from the use of observational data, eligible patients with confirmed COVID-19 were 1:1 propensityscore-matched to SARS-CoV-2-negative controls with a respiratory infection (matched controls). The probability of having a SARS-CoV-2 infection vs not was calculated through a multivariable logistic regression model that contained all baseline covariates (except for vital signs). The estimated propensity-score was used to match COVID-19 patients with nearest neighbor non-COVID-19 patients without replacement. Covariate balance after propensity-score matching was assessed using standardized differences. A standardized difference of less than 10\% indicated an adequate balance between groups. RAAS peptides have been log-transformed to achieve nearly normal distribution. After matching we used simple linear regression technique adjusting for left-censoring to assess changes in RAAS peptides. To investigate differences in RAAS peptide levels among patients taking RAAS inhibitors and those without, we stratified the analyses for patients on ACE inhibitors (ACEi) or angiotensinreceptor blockers (ARB) only, respectively. Changes within each group were tested with the use of a non-parametric Dunn's test to address multiple comparison performing Holm-Šidák stepwise adjustment. All $P$-values are twosided, all CIs are at the 95\% level. Statistical analyses were performed at an alpha-level of 5\% using Stata, version 15.1 (StataCorp LLC).

\section{Results}

\section{Patient characteristics}

Of the 103 patients with confirmed SARS-CoV-2 infection, 90 patients were eligible for propensity-score matching. Among 47 hospitalized medical patients with clinical suspicion for COVID-19 but with a negative RT-PCR for SARS-CoV-2, 43 patients were eligible for propensity-score matching. Finally, we generated 43 propensity-scorematched pairs (Fig. 1). Baseline characteristics of included patients after propensity-score matching are presented in Tables 1 and 2, respectively. Median age was 66 years in patients without and 67 years in patients with COVID-19. $53 \%$ of COVID-19 patients were male. Around 50\% of all patients had a known history of hypertension, 14\% had diabetes mellitus, and 30\% were obese. Mean age-adjusted Charlson Comorbidity Index was 4.6 points in nonCOVID-19 patients and 4.1 points in COVID-19 patients, emphasizing the high burden of multimorbidity in both groups. The prevalence of ACEi (19\%) and ARB (12-16\%) was well-balanced between the groups.

\section{Association of COVID-19 and RAAS peptide/ enzyme levels}

All measured equilibrium RAAS peptide levels were lower in patients with COVID-19 as compared with their controls. Not only serum levels of the vasoconstrictive and proinflammatory angiotensin I and II were lower in patients with COVID-19 but also the levels of the vasodilatory and anti-inflammatory angiotensin (1-7) and (1-5), respectively. Similar, the plasma-renin activity was reduced by around 59\% in COVID-19 patients. The relative between-group difference was at least 50\% for most angiotensins, revealing a strong downregulation of the RAAS in patients with COVID-19. However, plasma activities of both ACE and ACE2 did not significantly differ between the groups (Table 3 ). 


13 patients not included:
4 patients declined informed
consent
9 patients did not have
sufficient left-over blood
samples

103 hospitalized medical patients with positive SARSCoV-2 real-time-PCR between February 26th and April 30th, 2020

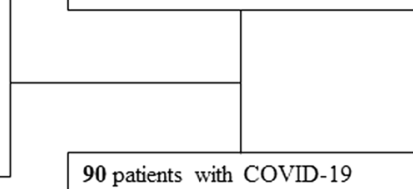

eligible for matching
47 hospitalized medical patients with negative SARS-CoV-2 real-time-PCR between February 26th and April 30th, 2020
4 patients not included: 4 patients declined informed consent
43 control patients eligible for matching

1:1 propensity-score COVID-19 eligible for RAASpeptide measurement and included in the final analysis

43 matched control patients eligible for RAAS-peptide measurement and included in the final analysis

\section{Figure 1}

Patient flowchart: selection of COVID-19 patients and their matched controls with SARS-CoV-2-negative respiratory infections. RAAS, renin-angiotensin-aldosterone system; SARS-CoV-2, severe acute respiratory syndrome coronavirus 2.

\section{RAAS peptide concentrations according to the use of RAAS inhibitors}

Figure 2A, B, C and D shows serum RAAS peptide concentrations in COVID-19 and non-COVID-19 patients treated with and without ACEi or ARB. Serum levels of angiotensin I were lower in patients without RAAS inhibitors as compared with patients on ACEi $(P=0.008)$ but remained unchanged in comparison to patients on ARB. Angiotensin II levels, however, were higher among patients not taking RAAS inhibitors as compared with ACEi $(P=0.019)$, but again, unchanged in patients with ARB. Considering angiotensin (1-5), serum concentrations were lower in patients taking ACEi $(P=0.046)$, even though this association was no more statistically significant after adjusting for multiple comparison. There was no difference in angiotensin (1-5) concentrations between patients not taking RAAS inhibitors and patients on ARB. Angiotensin (1-7) levels were higher among patients taking ACEi $(P=0.01)$ but did not change in the ARB subgroup as compared with patients without RAAS inhibitor.

As reported above, we observed a downregulation of the RAAS among patients with confirmed SARS-CoV-2 infection. Interestingly, this association was only found in patients not taking RAAS inhibitors, while there was no difference in RAAS peptide serum concentrations between
COVID-19 and non-COVID-19 patients taking RAAS inhibitors.

To address the association between betablocker intake and RAAS peptide levels, we performed a complementary analysis with patients taking betablockers without RAASinhibitors. Results for the 'betablocker only' group, however, were not different from findings of the reference group without RAAS inhibitors among all RAAS peptides of interest (data not shown).

\section{Enzymatic activity of renin, ACE, and ACE2 according to the use of RAAS inhibitors}

Figure 2E, F and $\mathrm{G}$ shows plasma activity levels of the main enzymes involved in the RAAS regulation. Plasma renin activity was comparable between patients with and without ACEi or ARB, respectively. However, among patients without RAAS inhibitors, the activity of plasma renin was decreased in patients with COVID-19. Patients on ACEi had significantly lower ACE $(P<0.0001)$ but higher ACE2 $(P=0.029)$ plasma activity as compared with those not taking pharmacological RAAS modulators. Both enzyme activities were not altered in patients taking ARB. Worth to note, the presence of COVID-19 was not associated with a change in plasma activities of renin, ACE, and ACE2, respectively. 
Table 1 Baseline characteristics of patients with and without COVID-19 after propensity-score matching.

\begin{tabular}{l}
\hline Characteristics \\
\hline Age, median (IQR), years \\
Male sex, $n$ (\%) \\
Cognitive impairment on admission, $n$ (\%) \\
Comorbidities, $n$ (\%) \\
Arterial hypertension \\
Chronic artery disease \\
Smoker \\
COPD \\
Chronic kidney disease \\
Diabetes \\
Cancer \\
Obesity (BMI > 30 kg/m²) \\
Asthma \\
OSA \\
ACCI, mean (s.D.) \\
Antihypertensive treatment, $n$ (\%) \\
ACE-inhibitor \\
Calcium-antagonist \\
Beta-blocker \\
AT 2 receptor blockers \\
Diuretic \\
Etiology of infection, $n$ (\%) \\
SARS-CoV-2 \\
Other virus - Rhinovirus \\
Bacteria \\
Escherichia coli \\
Pseudomonas aeruginosa, Hafnia alvei \\
Pseudomonas aeruginosa, Serratia marcescens \\
Staphylococcus aureus \\
Streptococcus pneumoniae \\
$\quad$ Mycoplasma pneumoniae \\
None \\
Systolic blood pressure, mmHg \\
Diastolic blood pressure, mmHg \\
Heart rate, beats per minute \\
Respiratory rate, per minute \\
Oxygen saturation, \% \\
Body temperature, ${ }^{\circ} \mathrm{C}$ \\
\hline
\end{tabular}

\begin{tabular}{|c|}
\hline No Covid-19 $(n=43)$ \\
\hline $\begin{array}{l}66(55,76) \\
20(47) \\
2(5)\end{array}$ \\
\hline $\begin{array}{r}22(51) \\
11(26) \\
7(18) \\
13(30) \\
7(16) \\
6(14) \\
14(33) \\
13(30) \\
5(12) \\
6(14) \\
4.6(3.0)\end{array}$ \\
\hline $\begin{array}{r}8(19) \\
9(21) \\
11(26) \\
7(16) \\
12(28)\end{array}$ \\
\hline $\begin{array}{c}0 \\
2(5)\end{array}$ \\
\hline $\begin{array}{c}2(5) \\
1(2) \\
1(2) \\
2(5) \\
1(2) \\
1(2) \\
33(77)\end{array}$ \\
\hline $\begin{array}{c}141(126,157) \\
82(72,96) \\
100(87,105) \\
21(18,24) \\
96(92,98) \\
37.5(36.7,38.3)\end{array}$ \\
\hline
\end{tabular}

\begin{tabular}{|c|c|}
\hline CoVID-19 $(n=43)$ & P-value \\
\hline $67(57,75)$ & 0.94 \\
\hline $23(53)$ & 0.52 \\
\hline $2(7)$ & 0.74 \\
\hline $21(49)$ & 0.83 \\
\hline $10(23)$ & 0.80 \\
\hline $5(15)$ & 0.71 \\
\hline $6(14)$ & 0.07 \\
\hline $8(19)$ & 0.78 \\
\hline $6(14)$ & 1.00 \\
\hline $8(19)$ & 0.14 \\
\hline $12(28)$ & 0.81 \\
\hline $5(12)$ & 1.00 \\
\hline $4(9)$ & 0.50 \\
\hline $4.1(3.5)$ & 0.51 \\
\hline $8(19)$ & 1.00 \\
\hline $8(19)$ & 0.79 \\
\hline $12(28)$ & 0.81 \\
\hline $5(12)$ & 0.53 \\
\hline $13(30)$ & 0.81 \\
\hline & $<0.001$ \\
\hline $43(100)$ & - \\
\hline 0 & - \\
\hline 0 & - \\
\hline 0 & - \\
\hline 0 & - \\
\hline 0 & - \\
\hline 0 & - \\
\hline 0 & - \\
\hline 0 & - \\
\hline $134(120,150)$ & 0.27 \\
\hline $77(69,86)$ & 0.10 \\
\hline $84(77,93)$ & $<0.001$ \\
\hline $22(19,25)$ & 0.32 \\
\hline $93(87,95)$ & 0.04 \\
\hline $37.6(37.2,38.3)$ & 0.34 \\
\hline
\end{tabular}

$\mathrm{ACCl}$, age adjusted Charlson comorbidity index; ACE, angiotensin converting enzyme; AT, angiotensin; COPD, chronic obstructive pulmonary disease; IQR, interquartile range; OSA, obstructive sleep apnea.

\section{Discussion}

This observational study investigated the association of COVID-19 and RAAS peptide levels as well as the activity of main RAAS enzymes stratified by the use of RAAS inhibitors and revealed two key findings: RAAS peptide concentrations were markedly lower in patients with COVID-19 as compared with their matched controls. However, the enzymatic activity of ACE and ACE2 two main RAAS modulators - were not altered in both groups. Secondly, as physiologically expected, there were relevant differences in RAAS peptide levels between patients with and those without current RAAS inhibitors.
Moreover, differences between patients with and without COVID-19, were only evident in patients not taking RAAS inhibitors.

As ACE2 is ubiquitously expressed in the lung, heart, and other human tissues $(1,3)$, early speculations arose that use of ACEi and ARB might be associated with higher risks of becoming infected with SARS-CoV-2 via an increased expression of ACE2 in the lung (21). In the meantime, however, culminating data from observational studies provided first evidence that the intake of RAAS inhibitors seems to be safe or rather beneficial in patients with COVID-19 and should not be withhold during the disease given a stable cardio-pulmonary condition $(8,9,22)$. 
Table 2 Baseline laboratory parameters for patients with and without COVID-19 after propensity-score matching. Data are presented as median (IQR).

\begin{tabular}{|c|c|c|c|}
\hline Parameters & No CoVID-19 $(n=43)$ & CoVID-19 $(n=43)$ & P-value \\
\hline \multicolumn{4}{|l|}{ Blood count } \\
\hline Haemoglobin, g/L & $131(115,148)$ & $132.5(120,143)$ & 0.84 \\
\hline Erythrocytes, T/L & $4.35(3.87,4.89)$ & $4.54(3.9,4.8)$ & 0.56 \\
\hline Leukocytes, G/L & $10.14(6.89,14.09)$ & $6.98(4.52,8.73)$ & 0.003 \\
\hline Thrombocytes, G/L & $238(181,336)$ & $210(178,295)$ & 0.48 \\
\hline Neutrophils, G/L & $6.11(5.14,10.68)$ & $3.56(2.84,6.68)$ & 0.013 \\
\hline Lymphocytes, G/L & $0.9(0.62,1.84)$ & $0.96(0.6,1.3)$ & 0.49 \\
\hline \multicolumn{4}{|l|}{ Coagulation } \\
\hline INR & $1.1(1.05,1.2)$ & $1.1(1,1.1)$ & 0.10 \\
\hline \multicolumn{4}{|l|}{ Chemistry } \\
\hline Sodium, mmol/L & $136(133,138)$ & $136(134,139)$ & 0.68 \\
\hline Potassium, mmol/L & $3.9(3.5,4.3)$ & $3.7(3.5,3.9)$ & 0.058 \\
\hline Glucose, $\mathrm{mmol} / \mathrm{L}$ & $6.3(5.7,7.2)$ & $6.6(6,7.8)$ & 0.40 \\
\hline Albumin, g/L & $30.5(26.5,34)$ & $30.4(28.2,32.9)$ & 0.93 \\
\hline Creatinine, $\mu \mathrm{mol} / \mathrm{L}$ & $87(60,109)$ & $87(66,110)$ & 0.99 \\
\hline $\mathrm{GFR}, \mathrm{mL} / \mathrm{min}$ & $74(47,90)$ & $76(53,90)$ & 0.74 \\
\hline Urea, $\mathrm{mmol} / \mathrm{L}$ & $5.4(4.4,8.3)$ & $5.05(3.7,7.05)$ & 0.34 \\
\hline ASAT, U/L & $23(17,38)$ & $36(30,45)$ & 0.003 \\
\hline ALAT, U/L & $27(20,41)$ & $31.5(26,44)$ & 0.14 \\
\hline Alkaline phosphatase, IU/L & $85(62,101)$ & $69.5(51.5,81)$ & 0.008 \\
\hline Gamma-glutamyl transferase, U/L & $43(31,92)$ & $45.5(27,83)$ & 0.77 \\
\hline $\mathrm{LDH}, \mathrm{IU} / \mathrm{L}$ & $224(167,255)$ & $325.5(243,459)$ & $<0.001$ \\
\hline $\mathrm{TSH}, \mathrm{mU} / \mathrm{L}$ & $1.37(1,2.44)$ & $1.24(0.75,2.94)$ & 0.54 \\
\hline $\mathrm{CRP}, \mathrm{mg} / \mathrm{L}$ & $70(16,135)$ & $77(39,125)$ & 0.35 \\
\hline Procalcitonin, $\mu g / L$ & $0.13(0.05,0.48)$ & $0.09(0.05,0.19)$ & 0.20 \\
\hline Interleukin 6, ng/L & $82(25,240)$ & $49(34,133)$ & 0.46 \\
\hline NT-pro-BNP, ng/L & $563.5(92,2732)$ & $438(182,1160)$ & 0.72 \\
\hline Troponin I, ng/L & $14.2(7.9,37)$ & $11.05(7.25,25.35)$ & 0.34 \\
\hline \multicolumn{4}{|l|}{ Blood gas analysis } \\
\hline Lactate, $\mathrm{mmol} / \mathrm{L}$ & $1.3(0.9,2.1)$ & $1.1(0.9,1.4)$ & 0.35 \\
\hline $\mathrm{pO} 2, \mathrm{mmHg}$ & $70(65,84)$ & $65(56,72.5)$ & 0.014 \\
\hline $\mathrm{pCO} 2, \mathrm{mmHg}$ & $35(31,44)$ & $31(29,34)$ & 0.016 \\
\hline Bicarbonate, $\mathrm{mmol} / \mathrm{L}$ & $23(21,26)$ & $23(21.15,25)$ & 0.67 \\
\hline $\mathrm{pH}$ & $7.42(7.365,7.485)$ & $7.47(7.45,7.49)$ & $<0.001$ \\
\hline $\mathrm{FiO} 2$ & $0.21(0.21,0.28)$ & $0.21(0.21,0.21)$ & 0.20 \\
\hline Horovitz ratio*, $\mathrm{mmHg}$ & $309.52(250,376.19)$ & $295.24(212.70,330.95)$ & 0.14 \\
\hline
\end{tabular}

*Ratio between $\mathrm{pO} 2$ and $\mathrm{FiO} 2$.

ALAT, alanine-aminotransferase; ARDS, acute respiratory distress syndrome; ASAT, aspartate-aminotransferase; CRP, C-reactive protein; FiO2, inspired oxygen fraction; GFR, glomerular filtration rate; INR, international normalized ratio; IQR, interquartile range; LDH, lactate dehydrogenase; NT-pro-BNP, $\mathrm{N}$-terminal-pro-B-type natriuretic peptide; $\mathrm{pCO} 2$, carbon dioxide partial pressure; $\mathrm{pO} 2$, oxygen partial pressure; TSH, thyroid stimulating hormone.

Nonetheless, human clinical data regarding the effects of RAAS inhibitors on COVID-19 patients' outcomes are still insufficient to definitively advise in favor or against treatment with RAAS inhibitors and call for randomized controlled trials.

To improve the understanding of the RAAS in presence of a SARS-CoV-2 infection, many research groups have provided potential explanations and mechanistical hypotheses $(22,23,24)$. Therein, the RAAS is composed of a cascade of regulatory peptides that interact in important physiological processes, including electrolyte and fluid balance, vascular permeability, and blood pressure regulation (2). ACE2, a membrane-bound aminopeptidase, has not only emerged as a host cell receptor for SARSCoV-2, but also as a potent counter-regulator of the RAAS (25). ACE2 degrades angiotensin I into the inactive angiotensin (1-9) and hydrolyzes angiotensin II into the effector peptide product angiotensin (1-7), that has vasodilatory, anti-proliferative, anti-inflammatory, and anti-fibrotic properties (26). To explore potential benefits by RAAS inhibitors in patients with COVID-19, Lubel \& Garg hypothesized on the basis of preclinical data that ACEi will attenuate the cleavage from angiotensin (1-7) into angiotensin (1-5), leading to higher levels of angiotensin (1-7) (27). This was also observed in more previous studies showing that ACE inhibition increased 
Table 3 RAAS peptides among patients with and without COVID-19. Data are presented as mean \pm S.D.

\begin{tabular}{l}
\hline \\
\hline RAAS peptides, pmol/L \\
Angiotensin I \\
Angiotensin II \\
Angiotensin (1-5) \\
Angiotensin (1-7) \\
Enzymatic activity, pmol/L \\
Plasma renin activity \\
Plasma ACE activity \\
Plasma ACE2 activity \\
\hline
\end{tabular}

No Covid-19 $(n=43)$
$66.8 \pm 6.8$
$92.5 \pm 6.4$
$6.6 \pm 3.4$
$7.6 \pm 4.7$
$207.9 \pm 5.5$
$1.9 \pm 2.9$
$0.07 \pm 0.3$

COVID-19 $(n=43)$

$31.6 \pm 5.7$

$37.7 \pm 4.9$

$3.3 \pm 2.2$

$4.8 \pm 2.9$

$88.6 \pm 4.5$

$1.8 \pm 2.2$

$0.09 \pm 0.3$

Relative between-group difference $(95 \% \mathrm{Cl})$

$A C E$, angiotensin-converting enzyme; RAAS, renin-angiotensin-aldosterone system

plasma levels of angiotensin (1-7) (28). However, other clinical data did not support this assumption as there was no influence of ACEi on angiotensin (1-7) concentrations in patients with coronary artery disease (29).

Based on this conflicting data with still scarce evidence on RAAS peptide alteration in the setting of a SARS-CoV-2 infection, we found no evidence of increased angiotensin I and II levels in patients with proven COVID-19. This observation challenges previous hypotheses that higher angiotensin II concentrations could be jointly responsible for the impressive clinical patterns of acute lung injury and pronounced myocardial damage in patients with SARS-CoV-2 infection (4). In line, a recent study found that COVID-19 patients are not characterized by major changes in plasma RAAS-activity including ACE-2 activity (10). Previous Chinese data have illustrated increased levels of angiotensin II among patients hospitalized with COVID-19 (6), however not comparing with SARS-CoV-2 negative controls to better estimate the independent association of COVID-19 and levels of angiotensin II. Interestingly, an earlier study in patients with avian influenza (H7N9) also showed increased levels of angiotensin II (30), again questioning the independence of the association in COVID-19 patients. However, as we found not only lower levels of angiotensin I and II but also lower concentrations of angiotensin (1-5) and (1-7), which both have been shown to have protective qualities (26), we may speculate whether a lack of protection might be a trigger for an unbalanced RAAS with detrimental pulmonary side effects in patients with COVID-19. Worth to note, we did not see any difference in plasma activity of ACE and ACE2 between both groups. Again, as there are only few clinical data comparing RAAS peptide measures between COVID-19 patients and comparable controls, including adjustment for main pharmaceutical RAAS modulators, one may only speculate whether ACE2 elevation is specific to SARS-CoV-2 infection or not.
Stratifying the analyses by the intake of either ACEi or ARB, we revealed three observations: First, the findings from this study were in line with previous studies, namely that upon presence of ACEi, the levels of angiotensin I were higher and the levels of angiotensin II were lower as compared with patients without RAAS blockage (31). Secondly, our results are confirming that the use of ACEi increases circulating levels of angiotensin (1-7) as previously shown in patients with chronic heart failure (28). Moreover, among patients taking ACEi, we found lower angiotensin (1-5) levels, a metabolite of angiotensin (1-7), catalyzed by ACE (32). Thirdly, similar to previous preclinical studies (33), plasma ACE activity was lower in patients taking ACEi, but unchanged among those taking ARB. Finally, as shown by previous - mostly animal and still conflicting - studies, level of ACE2 plasma activity was increased in patients taking ACEi but not among ARB takers (34). Confirming, the recent German study also found an increased plasma ACE2-activity in COVID-19 patients treated with ACEi (10). However, other studies did not find increased plasma ACE2 activity among patients who were taking ACEi as compared with untreated patients (35). Finally, careful interpretation is still recommended as data are lacking regarding the effects of RAAS inhibitors on lung-specific expression of ACE2.

As current clinical evidence is still insufficient to definitively advise RAAS inhibition during SARS-CoV-2 infection, this study revealed novel mechanistic insights of the RAAS regulation in hospitalized patients with COVID19. We measured main RAAS peptides and enzymes in patients with and without COVID-19, allowing better interpretability in this complex multiorgan failure setting. Moreover, mirroring a further strength of this study, we addressed confounding by indication by applying a propensity-score matching including SARS-CoV-2negative controls admitted with comparable clinical symptoms of a respiratory tract infection, and thus 

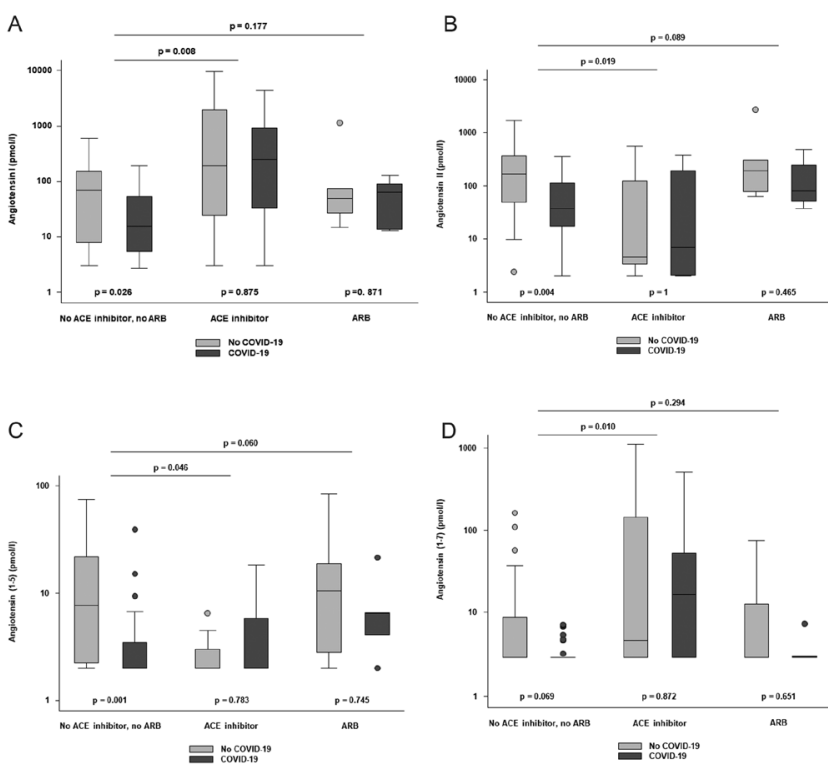

E
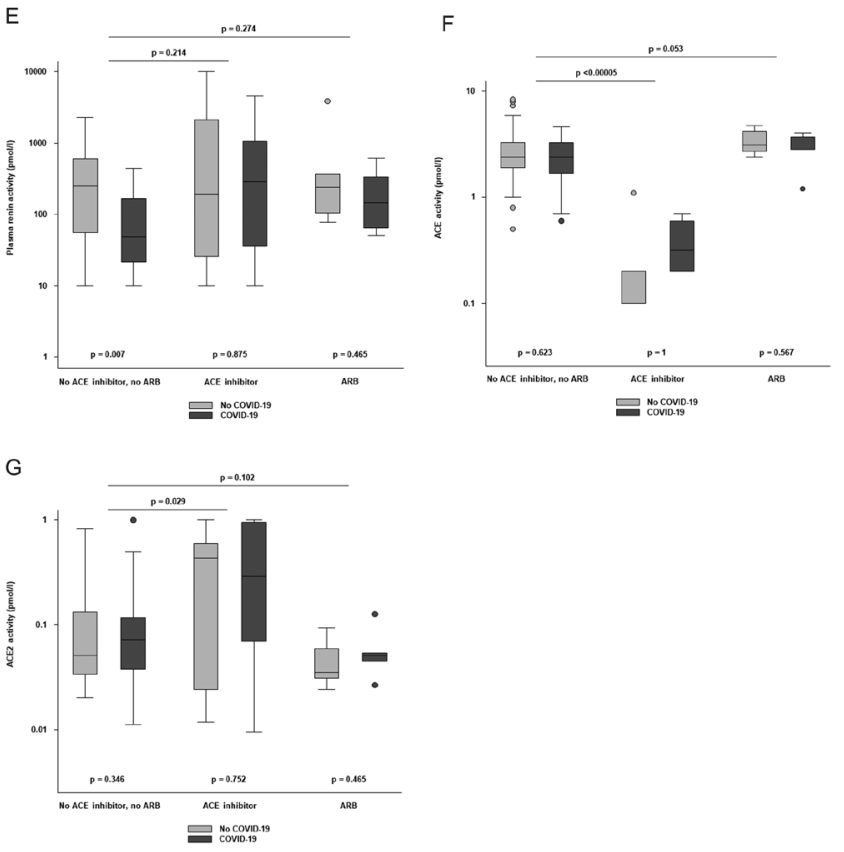

Figure 2

Serum RAAS peptide concentrations (A, B, C and D) and plasma activity levels ( $E, F$ and $G$ ) of main RAAS enzymes in COVID-19 and non-COVID-19 patients treated with and without RAAS inhibitors. ACE, angiotensin-converting enzyme, $A R B$, angiotensin-receptor blocker; IQR, interquartile range; RAAS, renin-angiotensin-aldosterone system. The boxes represent the 25 th and 75 th percentiles, horizontal lines within the boxes are the median value and the whiskers include values within 1.5-times IQR. The separated dots represent outliers. were able to better assess the independent association of COVID-19 and RAAS peptide modulation.

This study has limitations. Designed for explorative purposes, this monocentric study population was small, limiting external validity. Second, we assessed plasma ACE, and ACE2 activity and not tissue-specific expression patterns. Thus, we can only speculate that circulating concentrations are associated with tissue concentration. Thirdly, merely $50 \%$ of the hospitalized patients with COVID-19 within the first pandemic wave qualified for propensity-score matching with missing left-over blood samples being the most common reason for exclusion. Fourthly, we found a higher heart rate in patients without COVID-19, potentially affecting RAAS components. Based on the study design, we were not able to comprehensively assess the fluid state, a potential explanation for the relevant difference in heart rate between the two groups. However, as we did not observe a difference in the patients' sodium levels and other vital parameters, we do not think that the fluid state will be relevantly different between both groups. One potential explanation for this discrepancy may be the phenomenon of 'silent (happy) hypoxemia' (36) in patients with COVID-19 leading to lower levels of respiratory distress and heart rate as compared with patients suffering from conventional respiratory tract infections (37).

In conclusion, there is evidence that the RAAS is downregulated in patients admitted with COVID-19 as compared with SARS-CoV-2-negative matched controls presenting with comparable clinical features. While alteration of the RAAS among patients with COVID-19 was only observed in patients not on RAAS inhibition, further investigations are urgently needed to reproduce our findings and to explore whether adverse clinical outcomes in the COVID-19 setting is attributable to lower levels of - so-called - protective RAAS peptides and whether the administration of RAAS inhibitors is safe in COVID-19.

\section{Declaration of interest}

$\mathrm{O} \mathrm{D}$ works at Attoquant Diagnostics $\mathrm{GmbH}$ in Vienna, Austria, where the analysis of RAAS peptides was performed. All other authors have no conflicts of interest relevant to this paper.

\section{Funding}

This study was supported by Medical University Clinic of the Kantonsspital Aarau AG. 


\section{Author contribution statement}

$\mathrm{A} \mathrm{K}$ and A C designed the study, collected data and wrote the manuscript. C G edited the manuscript. S H and D K collected data and edited the manuscript. O D was responsible for the measurements of the RAAS peptides and edited the manuscript. L B was responsible for biobanking and laboratory measurements except RAAS peptides and edited the manuscript. B M edited the manuscript. P S designed the study and edited the manuscript. The first-author position was selected based on the fact that $\mathrm{A} K \mathrm{~K}$ had the idea of the study.

\section{Acknowledgements}

The authors thank all participating patients and their families, and all healthcare workers at the Kantonsspital Aarau for their great dedication to reduce the burden of this severe disease.

\section{References}

1 Hamming I, Timens W, Bulthuis ML, Lely AT, Navis G \& van Goor $\mathrm{H}$. Tissue distribution of ACE2 protein, the functional receptor for SARS coronavirus. A first step in understanding SARS pathogenesis. Journal of Pathology 2004203 631-637. (https://doi. org/10.1002/path.1570)

2 Gheblawi M, Wang K, Viveiros A, Nguyen Q, Zhong JC, Turner AJ, Raizada MK, Grant MB \& Oudit GY. Angiotensin-converting enzyme 2: SARS-CoV-2 receptor and regulator of the renin-angiotensin system: celebrating the 20th Anniversary of the Discovery of ACE2. Circulation Research 2020126 1456-1474. (https://doi.org/10.1161/ CIRCRESAHA.120.317015)

3 Li W, Moore MJ, Vasilieva N, Sui J, Wong SK, Berne MA, Somasundaran M, Sullivan JL, Luzuriaga K, Greenough TC et al. Angiotensin-converting enzyme 2 is a functional receptor for the SARS coronavirus. Nature $2003 \mathbf{4 2 6} 450-454$. (https://doi. org/10.1038/nature02145)

4 Kuba K, Imai Y, Rao S, Gao H, Guo F, Guan B, Huan Y, Yang P, Zhang $\mathrm{Y}$, Deng $\mathrm{W}$ et al. A crucial role of angiotensin converting enzyme 2 (ACE2) in SARS coronavirus-induced lung injury. Nature Medicine 200511 875-879. (https://doi.org/10.1038/nm1267)

5 Sodhi CP, Wohlford-Lenane C, Yamaguchi Y, Prindle T, Fulton WB, Wang S, McCray PB, Jr, Chappell M, Hackam DJ \& Jia H. Attenuation of pulmonary ACE2 activity impairs inactivation of des-Arg(9) bradykinin/BKB1R axis and facilitates LPS-induced neutrophil infiltration. American Journal of Physiology: Lung Cellular and Molecular Physiology 2018314 L17-L31. (https://doi.org/10.1152/ ajplung.00498.2016)

6 Liu Y, Yang Y, Zhang C, Huang F, Wang F, Yuan J, Wang Z, Li J, Feng C, Zhang $Z$ et al. Clinical and biochemical indexes from 2019$\mathrm{nCoV}$ infected patients linked to viral loads and lung injury. Science in China 202063 364-374.

7 Sommerstein R, Kochen MM, Messerli FH \& Grani C. Coronavirus Disease 2019 (COVID-19): do angiotensin-converting enzyme inhibitors/angiotensin receptor blockers have a biphasic effect? Journal of the American Heart Association 20209 e016509. (https://doi. org/10.1161/JAHA.120.016509)

8 de Abajo FJ, Rodriguez-Martin S, Lerma V, Mejia-Abril G, Aguilar M, Garcia-Luque A, Laredo L, Laosa O, Centeno-Soto GA, Angeles Galvez $\mathrm{M}$ et al. Use of renin-angiotensin-aldosterone system inhibitors and risk of COVID-19 requiring admission to hospital: a case-population study. Lancet 2020395 1705-1714. (https://doi. org/10.1016/S0140-6736(20)31030-8)

9 Reynolds HR, Adhikari S, Pulgarin C, Troxel AB, Iturrate E, Johnson SB, Hausvater A, Newman JD, Berger JS, Bangalore S et al. Renin-angiotensin-aldosterone system inhibitors and risk of covid-19. New England Journal of Medicine 2020382 2441-2448. (https://doi.org/10.1056/NEJMoa2008975)

10 Kintscher U, Slagman A, Domenig O, Rohle R, Konietschke F, Poglitsch M \& Mockel M. Plasma angiotensin peptide profiling and ACE (angiotensin-converting enzyme)-2 activity in COVID19 patients treated With pharmacological blockers of the reninangiotensin system. Hypertension 202076 e34-e36. (https://doi. org/10.1161/HYPERTENSIONAHA.120.15841)

11 Gregoriano C, Koch D, Haubitz S, Conen A, Fux CA, Mueller B, Bernasconi L, Hammerer-Lercher A, Oberle M, Burgermeister S et al. Characteristics, predictors and outcomes among 99 patients hospitalised with COVID-19 in a tertiary care centre in Switzerland: an observational analysis. Swiss Medical Weekly 2020150 w20316. (https://doi.org/10.4414/smw.2020.20316)

$12 \mathrm{WHO}$. Clinical management of severe acute respiratory infection when novel conovirus (nCov) infection is supsected; interim guidance. 2020. WHO REFERENCE NUMBER: WHO/2019-nCoV/ clinical/2020.5, (https://www.who.int/publications/i/item/clinicalmanagement-of-covid-19) last accessed February 18, 2021.

13 Charlson M, Szatrowski TP, Peterson J \& Gold J. Validation of a combined comorbidity index. Journal of Clinical Epidemiology $1994 \mathbf{4 7}$ 1245-1251. (https://doi.org/10.1016/0895-4356(94)90129-5)

14 Juma S, Taabazuing MM \& Montero-Odasso M. Clinical frailty scale in an acute medicine unit: a simple tool that predicts length of stay. Canadian Geriatrics Journal 201619 34-39. (https://doi.org/10.5770/ cgj.19.196)

15 Summary of Allplex ${ }^{T M}$ 2019-nCoV Assay performance data. Seegene Inc., 2020. (available at: http://www.seegene.com/upload/product/ Allplex_2019_nCoV_performance_data.pdf). Last accessed on 11 January 2021.

16 Urwyler SA, Ebrahimi F, Burkard T, Schuetz P, Poglitsch M, Mueller B, Donath MY, Christ-Crain M. IL (Interleukin)-1 receptor antagonist increases Ang (angiotensin. (1-7]) and decreases blood pressure in obese individuals. Hypertension 202075 1455-1463. (https://doi. org/10.1161/HYPERTENSIONAHA.119.13982)

17 Guo Z, Poglitsch M, McWhinney BC, Ungerer JPJ, Ahmed AH, Gordon RD, Wolley M \& Stowasser M. Measurement of equilibrium angiotensin II in the diagnosis of primary aldosteronism. Clinical Chemistry 202066 483-492. (https://doi.org/10.1093/clinchem/ hvaa001)

18 Pavo N, Goliasch G, Wurm R, Novak J, Strunk G, Gyongyosi M, Poglitsch M, Saemann MD \& Hulsmann M. Low- and highrenin heart failure phenotypes with clinical implications. Clinical Chemistry 201864 597-608. (https://doi.org/10.1373/ clinchem.2017.278705)

19 Guo Z, Poglitsch M, Cowley D, Domenig O, McWhinney BC, Ungerer JPJ, Wolley M \& Stowasser M. Effects of ramipril on the aldosterone/renin ratio and the aldosterone/angiotensin II ratio in patients with primary aldosteronism. Hypertension 202076 488-496. (https://doi.org/10.1161/HYPERTENSIONAHA.120.14871)

20 Zoufaly A, Poglitsch M, Aberle JH, Hoepler W, Seitz T, Traugott M, Grieb A, Pawelka E, Laferl H, Wenisch C et al. Human recombinant soluble ACE2 in severe COVID-19. Lancet: Respiratory Medicine 20208 1154-1158. (https://doi.org/10.1016/S22132600(20)30418-5)

21 Fang L, Karakiulakis G \& Roth M. Are patients with hypertension and diabetes mellitus at increased risk for COVID-19 infection? Lancet: Respiratory Medicine 20208 e21. (https://doi.org/10.1016/S22132600(20)30116-8)

22 Vaduganathan M, Vardeny O, Michel T, McMurray JJV, Pfeffer MA \& Solomon SD. Renin-angiotensin-aldosterone system inhibitors in patients with Covid-19. New England Journal of Medicine 2020382 1653-1659. (https://doi.org/10.1056/NEJMsr2005760)

23 Brojakowska A, Narula J, Shimony R \& Bander J. Clinical implications of SARS-CoV-2 interaction with renin angiotensin system: JACC review topic of the week. Journal of the American 
College of Cardiology 202075 3085-3095. (https://doi.org/10.1016/j. jacc.2020.04.028)

24 Ingraham NE, Barakat AG, Reilkoff R, Bezdicek T, Schacker T, Chipman JG, Tignanelli CJ \& Puskarich MA. Understanding the renin-angiotensin-aldosterone-SARS-CoV axis: a comprehensive review. European Respiratory Journal 202056 2000912. (https://doi. org/10.1183/13993003.00912-2020)

25 Poduri R, Joshi G \& Jagadeesh G. Drugs targeting various stages of the SARS-CoV-2 life cycle: exploring promising drugs for the treatment of Covid-19. Cellular Signalling 202074 109721. (https:// doi.org/10.1016/j.cellsig.2020.109721)

26 Simões E Silva AC \& Teixeira MM. ACE inhibition, ACE2 and angiotensin-(1-7) axis in kidney and cardiac inflammation and fibrosis. Pharmacological Research 2016107 154-162. (https://doi. org/10.1016/j.phrs.2016.03.018)

27 Lubel J \& Garg M. Renin-angiotensin-aldosterone system inhibitors in Covid-19. New England Journal of Medicine $2020382 \mathrm{e} 92$. (https:// doi.org/10.1056/NEJMc2013707)

28 Patel VB, Bodiga S, Fan D, Das SK, Wang Z, Wang W, Basu R, Zhong J, Kassiri Z \& Oudit GY. Cardioprotective effects mediated by angiotensin II type 1 receptor blockade and enhancing angiotensin 1-7 in experimental heart failure in angiotensin-converting enzyme 2-null mice. Hypertension 201259 1195-1203. (https://doi. org/10.1161/HYPERTENSIONAHA.112.191650)

29 Campbell DJ, Zeitz CJ, Esler MD \& Horowitz JD. Evidence against a major role for angiotensin converting enzyme-related carboxypeptidase (ACE2) in angiotensin peptide metabolism in the human coronary circulation. Journal of Hypertension 200422 1971-1976. (https://doi.org/10.1097/00004872-200410000-00020)

30 Yang P, Gu H, Zhao Z, Wang W, Cao B, Lai C, Yang X, Zhang L, Duan Y, Zhang $S$ et al. Angiotensin-converting enzyme 2 (ACE2) mediates influenza H7N9 virus-induced acute lung injury. Scientific Reports 20144 7027. (https://doi.org/10.1038/srep07027)

31 Johnston CI, Millar JA, McGrath BP \& Matthews PG. Long-term effects of captopril (SQ14 225) on blood-pressure and hormone levels in essential hypertension. Lancet 19792 493-496. (https://doi. org/10.1016/s0140-6736(79)91552-6)

32 Yu L, Yuan K, Phuong HT, Park BM \& Kim SH. Angiotensin-(1-5), an active mediator of renin-angiotensin system, stimulates ANP secretion via Mas receptor. Peptides 201686 33-41. (https://doi. org/10.1016/j.peptides.2016.09.009)

33 Burrell LM, Gayed D, Griggs K, Patel SK \& Velkoska E. Adverse cardiac effects of exogenous angiotensin 1-7 in rats with subtotal nephrectomy are prevented by ACE inhibition. PLOS ONE 201712 e0171975. (https://doi.org/10.1371/journal.pone.0171975)

34 Burchill LJ, Velkoska E, Dean RG, Griggs K, Patel SK \& Burrell LM. Combination renin-angiotensin system blockade and angiotensinconverting enzyme 2 in experimental myocardial infarction: implications for future therapeutic directions. Clinical Science 2012 123 649-658. (https://doi.org/10.1042/CS20120162)

35 Ramchand J, Patel SK, Kearney LG, Matalanis G, Farouque O, Srivastava PM \& Burrell LM. Plasma ACE2 activity predicts mortality in aortic stenosis and is associated with severe myocardial fibrosis. JACC: Cardiovascular Imaging 202013 655-664. (https://doi. org/10.1016/j.jcmg.2019.09.005)

36 Couzin-Frankel J. The mystery of the pandemic's 'happy hypoxia'. Science 2020368 455-456. (https://doi.org/10.1126/ science.368.6490.455)

37 Simonson TS, Baker TL, Banzett RB, Bishop T, Dempsey JA, Feldman JL, Guyenet PG, Hodson EJ, Mitchell GS, Moya EA et al. Silent hypoxaemia in COVID-19 patients. Journal of Physiology 2021 599 1057-1065. (https://doi.org/10.1113/JP280769)

Received 16 December 2020

Revised version received 13 January 2021

Accepted 3 February 2021 